\title{
Prevalence of medication-related falls in 200 consecutive elderly patients with hip fractures: a cross-sectional study
}

Charlotte Uggerhøj Andersen ${ }^{1,2,3^{*}}$, Pernille Overgaard Lassen ${ }^{4}$, Hussain Qassim Usman ${ }^{4}$, Nadja Albertsen ${ }^{4}$, Lars Peter Nielsen ${ }^{1,3}$ and Stig Andersen ${ }^{2,4}$

\begin{abstract}
Background: Hip fractures constitute a major health problem in elderly people and are often fall-related. Several factors can contribute to a fall episode leading to hip fracture, including fall-risk-increasing drugs (FRIDs), which are often used by elderly people.

We aimed to investigate the prevalence of medication-related falls and to assess the role of FRIDs and potentially inappropriate medications (PIMs) in a population of elderly patients hospitalized for a hip fracture.

Methods: We reviewed the patient records of 200 consecutive patients, aged $\geq 65$ years, who were admitted for a hip fracture and evaluated whether medications were likely to have contributed to the fall episode. PIMs were identified using the Screening Tool of Older Persons' Prescriptions version 2 (STOPP) and by evaluating indications, contra-indications and interactions of the prescribed medications for each patient.
\end{abstract}

Results: FRIDs were used by 175 patients (87.5\%). Medications were considered a likely contributor to the fall in 82 patients (41\%). These were most often psychotropic medications alone or in combination with antihypertensives and/or diuretics. The 82 patients with suspected medication-related falls used more medications, FRIDs and PIMs than the rest of the patients, and in 74 (90\%) of the 82 patients, at least one medication considered to be a contributor to the fall was also a PIM.

Conclusions: The prevalence of suspected medication-related falls was $41 \%$. It seems likely that a medication review could have reduced, though not eliminated, the risk of falling in this group of patients.

Keywords: Fall-risk-increasing drugs, Potentially inappropriate medication, Fall, Polypharmacy, Geriatrics

\section{Background}

A hip fracture is associated with considerable socioeconomic costs [1] and constitutes a high-risk situation for an elderly patient, as the mortality for patients older than 65 years is $12-35 \%$ within the first year after the fracture [2] and remains elevated for several years [3].

\footnotetext{
* Correspondence: c.uggerhoej@rn.dk

${ }^{1}$ Department of Clinical Pharmacology, Aalborg University Hospital, Mølleparkvej 8, 9000 Aalborg, Denmark

${ }^{2}$ Department of Clinical Medicine, Aalborg University, Aalborg, Denmark Full list of author information is available at the end of the article
}

Several medications have been identified as fall-riskincreasing drugs (FRIDs) [4-8]. The association between an increased risk of falling and the use of psychotropic medications, such as antidepressants, antipsychotics and benzodiazepines, seems well established, as indicated by odds ratios ranging from 1.3 to 2 in a recent metanalysis [8]. The association between falls and the use of cardiovascular medications, including antihypertensives and antiarrhythmics, does not seem quite as consistent [6]. However, in clinical practice, cardiovascular medications are often regarded as FRIDs, $[9,10]$ as their adverse

(C) The Author(s). 2020 Open Access This article is licensed under a Creative Commons Attribution 4.0 International License, which permits use, sharing, adaptation, distribution and reproduction in any medium or format, as long as you give appropriate credit to the original author(s) and the source, provide a link to the Creative Commons licence, and indicate if changes were made. The images or other third party material in this article are included in the article's Creative Commons licence, unless indicated otherwise in a credit line to the material. If material is not included in the article's Creative Commons licence and your intended use is not permitted by statutory regulation or exceeds the permitted use, you will need to obtain permission directly from the copyright holder. To view a copy of this licence, visit http://creativecommons.org/licenses/by/4.0/ The Creative Commons Public Domain Dedication waiver (http://creativecommons.org/publicdomain/zero/1.0/) applies to the data made available in this article, unless otherwise stated in a credit line to the data. 
effects can directly or indirectly cause dizziness, hypotension and orthostatic hypotension. Several reports have shown that more than $90 \%$ of elderly people experiencing a fall or a hip fracture are taking FRIDs $[10,11]$. Thus, FRIDs can be regarded as a modifiable risk factor. Furthermore, a recent study showed that $85 \%$ of elderly patients with a hip fracture were prescribed potentially inappropriate medications (PIMs), which may be unnecessary or entail a high risk of adverse effects [12]. The Screening Tool of Older Persons' Prescriptions (STOPP) [13] may guide the performance of a medication review, both by pointing out situations in which certain medications are potentially inappropriate and by identifying certain FRIDs as PIMs.

Given the high prevalence of FRIDs and PIMs among elderly patients, it may be hypothesized that medication reviews and interventions to reduce FRIDs and PIMs in this group would effectively reduce the risk of falling. However, two recent randomized studies investigating the effect of FRID-withdrawal among more than 600 elderly people experiencing a fall [9], and the effect of medication reviews [14] among 199 elderly patients with hip fractures [14] did not find an effect of these interventions on the rate of falls during a 12-month followup period. Possible explanations include competing risk factors for falling, such as comorbidities, and impaired cognition, balance, or vision. In addition, extrinsic factors influencing the subject $[15,16]$ may play a role in many falls.

Even though the prevalence of FRID users among patients with a hip fracture is high, it is not known how often FRIDs actually contribute to the fall. This knowledge is essential to understanding how much the incidence of hip fracture could potentially be reduced by stopping the use of these medications. Thus, the aims of our study were to estimate the prevalence of medication-related falls leading to a hip fracture in a population of elderly patients admitted to a joint orthopaedic and geriatric ward and to assess the role of FRIDs and PIMs.

\section{Methods}

\section{Study design and population}

This study was a retrospective cross-sectional study. Two hundred consecutive patients with hip fracture, aged 65 years or older, admitted to a Danish University Hospital during a period of 24 weeks in 2017 were identified by a search in the hospital's database using the ICD-10 codes for fracture of the femur (DS72-DS729).

\section{Evaluation and definition of medication-related falls, FRIDs and PIMs}

A consultant in Clinical Pharmacology (CUA) reviewed all patient records, focusing on 1) the description of the fall episode, including fall-related symptoms and the conclusions regarding the causes of the fall, made by the attending geriatrician during admission; 2) comorbidities, demographic data and medication list at the time of admission; 3) blood pressure, respiratory frequency, peripheral saturation, body temperature and heart rate at the time of and during admission; 4) laboratory data including c-reactive protein, leucocyte count, electrolytes, haemoglobin, liver and renal parameters, and blood glucose; 5) the results of other diagnostic evaluations performed during admission; and 6) medication withdrawals or changes during admission.

FRIDs were defined in accordance with previous work on fall-risk-related medications [6-8, 13, 17, 18]: 1) psychotropic medications (antidepressants, antipsychotics, antiepileptic medications, medications for Parkinson's disease, medications for dementia, first-generation antihistamines, benzodiazepines or benzodiazepine-like medications (zopiclone and zolpidem) and opioids); 2) cardiovascular medications (calcium antagonists, angiotensin converting enzyme (ACE)-inhibitors, angiotensin-II receptor (AT-II) antagonists, beta-adrenoceptor antagonists, alpha-adrenoceptor antagonists, diuretics, nitrous vasodilators, and anti-arrhythmic medications); and 3) urinary antispasmodics. PIMs were identified by review of the patients' medication lists according to the STOPP version 2, [13] available from the Danish Geriatric Society. Furthermore, the indications, contra-indications and interactions for each prescribed medication, as listed in the Summary of Product Characteristics found on the homepage of the Danish Medicines Agency, were also considered for each patient. All data mentioned above was entered in case report forms during the initial review.

The clinical pharmacologist excluded a suspected medication-related fall if a patient had not experienced a fall, was not using any medications or FRIDs, or if a nonmedication-related fall cause was described in the patient record. Otherwise, the clinical pharmacologist and a consultant in Geriatrics (POL, HU, or NA) discussed the case in order to obtain a consensus about whether one or more medications were likely contributors to the fall. Medications were generally considered likely contributors to the fall if their effects, adverse effects or interactions could have caused or aggravated symptoms or clinical findings related to the fall episode, for example, orthostatic hypotension. If we concluded that medications were likely contributors to the fall, we defined the patient as having had a suspected medication-related fall. If the fall was more likely explained by the consequences of acute or chronic disease, tripping or extrinsic factors, we did not consider medications likely contributors. Patients who were not attended by an on-site geriatrician during admission were evaluated retrospectively following the same procedure as that used for the rest of the patients. 


\section{Data handling and statistical analysis}

Study data were collected and managed using REDCap (Vanderbilt, USA) electronic data capture tools hosted at Aalborg University. REDCap is a secure, web-based application designed to support data capture for research studies [19]. Data were exported for statistical analysis or graphics in STATA (StataCorp. 2017. Stata Statistical Software: Release 15. College Station, TX: StataCorp LLC). The distribution of variables was evaluated according to histograms and Q-norm plots, and data that had a normal distribution were summarized as means \pm standard deviations (SDs). Variables that were not normally distributed were summarized by medians [25th percentile, 75th percentile], and differences between two groups were tested by the Wilcoxon rank-sum test. Differences in the prevalence of diseases between patients with and without a suspected medication-related fall were analysed by two-sample z-test. Differences in age, clinical data and the number of medications and FRIDs among multiple groups were analysed by regression with a bootstrap analysis. The differences between proportions of patients with PIMs among multiple groups were compared by pairwise two-sample z-tests. Power calculation to estimate study size was not performed due to lack of data to support this. Analyses were performed without imputation of missing data. The number of patients with missing data are indicated for each variable in footnotes of tables. Percentages of patients with a given condition (e.g. sodium $<132 \mathrm{mmol} / \mathrm{l}$ ) were calculated by dividing the number of confirmed cases with the total number of patients in the population (200).

\section{Results}

Prevalence of suspected medication-related falls

A fall preceded the hip fracture in 197 (98.5\%) patients, and the fall was considered a low energy trauma, indicating an osteoporotic fracture, in 175 (87.5\%) patients. Three patients (1.5\%) (group 1) did not experience a fall, and eight (4\%) (group 2) did not take any medication. In 59 patients (29.5\%) (group 3), the fall episode seemed more likely to have been caused by an extrinsic factor, such as a push by a large animal or another person, or tripping. Consequences of a chronic or acute disease, such as influenza, urinary tract infection or uncontrolled atrial fibrillation, were considered the main cause of the fall in 48 patients (24\%) (group 4). Finally, we considered $82(41 \%)$ patients as having had a suspected medicationrelated fall (group 5) (Fig. 1). The most frequent reason for medications to be regarded as a contributor to the fall was dizziness in patients using medications with dizziness as a known adverse effect $(n=21 \quad(10.5 \%))$, followed by the presence of low blood pressure or symptoms of orthostatic hypotension in patients who were using medications able to decrease blood pressure $(n=$
$17(8.5 \%))$. Medications were suspected to contribute to a fall by impairing the functional level in 12 patients (6\%) and to contribute to accidental happenings leading to a fall by influencing cognition or balance in 11 patients (5.5\%). In both instances, psychotropic drugs were the most commonly involved. Diuretics were thought to play a role by inducing hyponatremia in four patients (2\%). Finally, the circumstances of the fall episode were not well described in 17 patients (8.5\%), but the presence of FRIDs and no other obvious causes of the fall led us to define these as having had a suspected medicationrelated fall.

A consultant geriatrician had performed an onsite evaluation of 170 (85\%) of the patients in the study population during admission.

\section{Demographics, comorbidities and use of medication in the total population}

A summary of the populations' demographic and clinical characteristics is shown in Table 1.

One or more comorbidities were present in 195 (97.5\%) patients, and the most common comorbidities were hypertension, osteoporosis and atrial fibrillation (Table 2).

The median number of prescribed medications used at admission was seven, ranging from 0 to 27. At least 1 FRID was prescribed to $175(87.5 \%)$ patients, and the median number of used FRIDs was three, ranging from zero to seven. A detailed list of medications used at the time of admission is available in Table $1 S$ in the on-line supplementary material.

\section{Characteristics of patients with a suspected medication- related fall}

The group of patients with a suspected medicationrelated fall was markedly older than the group in which an extrinsic factor or tripping was considered the most likely reason (group 3). Otherwise, only the number of prescribed medications and FRIDs at the time of admission and the proportion of PIMs were significantly higher in patients with a suspected medication-related fall than in patients in the other groups (Table 3). Regarding comorbidities, patients with a suspected medicationrelated fall had a higher prevalence of osteoporosis and ischaemic heart disease when compared to the rest of the patients (Table 2).

\section{Medications playing a role in the fall episode}

One medication was considered likely to play a role in the fall episode in 16 (19.5\%) patients, and more than one medication was considered likely to a role in the fall episode in $66(80.5 \%)$ of the 82 patients with a suspected medication-related fall. All medications suspected to contribute to falls were FRIDs. 


\section{Total population: $\mathbf{n}=\mathbf{2 0 0}(100 \%)$}

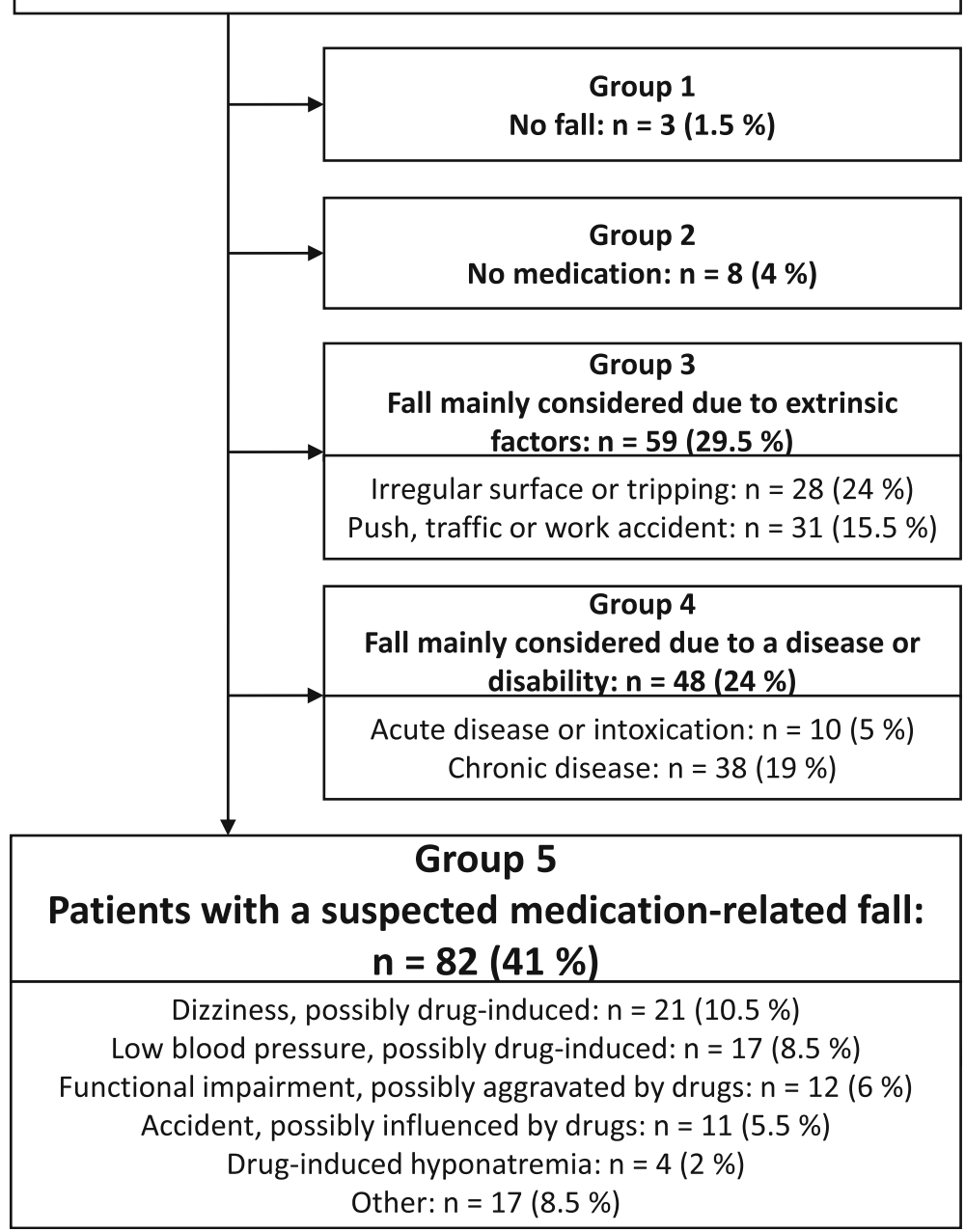

Fig. 1 Main causes of falls. Figure 1. Flow diagram showing the selection procedure for the patients having a medication-related fall, as evaluated with the joint expertise of a clinical pharmacologist and a geriatrician

Psychotropic medications, including antidepressants, benzodiazepines, benzodiazepine-like medications, antipsychotics, antiepileptics and opioids, were suspected of contributing in 68 (83\%) patients, whereas antihypertensive medications and diuretics likely played a role in $30(36.5 \%)$ and $29(35 \%)$ of the 82 patients with a suspected medication-related fall, respectively. The medication subclasses likely to have contributed to the fall episodes in more than five patients are shown in Fig. 2.

PIMs.

PIMs were identified in 141 patients (70.5\%). Among patients with a suspected medication-related fall, PIMs were identified in 79 (96\%) patients compared to $62(52 \%)$ of the 118 patients without a suspected medication-related fall $(p<0.001)$. In $74(90 \%)$ of the 82 patients with a suspected medication-related fall (37\% of the total population), PIMs were suspected to have contributed directly to the fall leading to admission. A single medication was considered both a PIM and a contributor to the fall in 36 (44\%) patients, and more than one medication was considered a PIM and contributor to the fall in $38(46 \%)$ of the 82 patients with a suspected medication-related fall. In 42 $(51 \%)$ of the patients with a suspected medication-related fall, the number of medications found likely to be involved in the fall episode was higher than the number of identified PIMs.

\section{Discussion}

We found that the prevalence of suspected medicationrelated falls leading to hip a fracture among elderly 
Table 1 Characteristics of the study population

\begin{tabular}{|c|c|}
\hline \multicolumn{2}{|l|}{ General characteristics } \\
\hline Female $(n(\%))$ & $136(68)$ \\
\hline Age (years) & $82[76,88]$ \\
\hline Age > 80 years $(n(\%))$ & $115(57.5)$ \\
\hline Height (cm) & $166 \pm 9 \mathrm{~cm}$ \\
\hline Weight (kg) & $67 \pm 14 \mathrm{~kg}$ \\
\hline Body mass index $\left(\mathrm{kg} / \mathrm{m}^{2}\right)$ & $24 \pm 4$ \\
\hline Body mass index < $18.5(n(\%))$ & $17(8.5)$ \\
\hline \multicolumn{2}{|l|}{ Residence ( $n(\%))$} \\
\hline Private home & $158(79)$ \\
\hline Nursing home & $35(17.5)$ \\
\hline Other & $9(4.5)$ \\
\hline \multicolumn{2}{|l|}{ Type of fall and fracture ( $n(\%))$} \\
\hline $\begin{array}{l}\text { Low-energy trauma defining an } \\
\text { osteoporotic fracture }\end{array}$ & $175(87.5)$ \\
\hline Not low-energy trauma & $22(11)$ \\
\hline No fall & $3(1.5)$ \\
\hline \multicolumn{2}{|l|}{ Clinical findings ( $n(\%)$ ) } \\
\hline First SBP at admission $<120 \mathrm{mmHg}$ & $12(6)$ \\
\hline $\begin{array}{l}\text { Lowest measured SBP during } \\
\text { the admission }<120 \mathrm{mmHg}\end{array}$ & $135(67.5)$ \\
\hline First PS at admission < $90 \%$ & $22(11)$ \\
\hline First RF at admission $>20 / \mathrm{min}$ & $23(11.5)$ \\
\hline First $\mathrm{TP}>38.0^{\circ} \mathrm{C}$ & $11(5.5)$ \\
\hline \multicolumn{2}{|l|}{$\begin{array}{l}\text { Abnormal laboratory findings at } \\
\text { the time of admission }(n(\%))\end{array}$} \\
\hline $\begin{array}{l}\text { Estimated glomerular filtration } \\
\text { rate }^{*}<60 \mathrm{ml} / \mathrm{min}\end{array}$ & $74(37)$ \\
\hline $\begin{array}{l}\text { Estimated glomerular filtration } \\
\text { rate }^{*}<30 \mathrm{ml} / \mathrm{min}\end{array}$ & $13(6.5)$ \\
\hline C-reactive protein > $100 \mathrm{mg} / \mathrm{l}$ & $12(6)$ \\
\hline Haemoglobin < 6 mmol// & $11(5.5)$ \\
\hline Sodium < $132 \mathrm{mmol} / \mathrm{l}$ & $12(6)$ \\
\hline Potassium < $3.2 \mathrm{mmol} / \mathrm{l}$ & $5(2.5)$ \\
\hline $\begin{array}{l}\text { Thyroid stimulating hormone } \\
<0.3 \mathrm{~m} \mathrm{IU} / \mathrm{l} \text { or }>4.5 \mathrm{mIU} / \mathrm{l}\end{array}$ & $20(10)$ \\
\hline $\begin{array}{l}\text { Alanine amino transferase } \\
>50 \mathrm{U} / \mathrm{l} \text { in men or }>35 \mathrm{U} / \mathrm{l} \text { in women }\end{array}$ & $12(6)$ \\
\hline Glucose $<4 \mathrm{mmol} / \mathrm{l}$ & $0(0)$ \\
\hline Glucose $>10 \mathrm{mmol} / \mathrm{l}$ & $14(7)$ \\
\hline Albumin $<34 \mathrm{~g} / \mathrm{l}$ & $69(34.5)$ \\
\hline
\end{tabular}

Table 1. Detailed description of the characteristics of the study population. Abbreviations: CNS central nervous system SBP systolic blood pressure, PS peripheral saturation, $R F$ respiratory frequency, $T P$ body temperature. *: calculated by the EPI-CKD formula. Number of patients with missing data for each variable: age: 0 , height: 10 , weight: 17 , body mass index: 24 , first SBP: 2 lowest SBP: 8, PS: 4, RF: 4, TP: 8, Estimated glomerular filtration rate: 1, Creactive protein: 9 , Haemoglobin: 3 , sodium: 2 , potassium: 2 , thyroid stimulating hormone: 37, alanine amino transferase: 8 , glucose: 16, albumin: 2 . Percentages of patients with a given condition (e.g. sodium $<132 \mathrm{mmol} / \mathrm{l}$ ) were calculated by dividing the number of confirmed cases with the total number of patients in the population (200) patients was $41 \%$. Furthermore, we identified at least one of the medications found to contribute to the fall as potentially inappropriate in $90 \%$ of patients with a suspected medication-related fall.

The clinical data point to an influence of factors other than medication, e.g., extrinsic sources or chronic or acute illness, in the incident leading to a hip fracture in more than half of the patients. However, the estimated $41 \%$ prevalence of suspected medication-related falls suggests that medications are a major risk factor. We have not identified other studies estimating the prevalence of medication-related falls in hip fracture patients, and we were expecting a higher occurrence of suspected medication-related falls due to the frequent use of FRIDs in hip fracture patients $[10,11]$. Medications can be considered modifiable risk factors, and we identified an overlap between medications found to contribute to the fall episode and medications identified as PIMs in the majority of the patients with a suspected medicationrelated fall. Interestingly, the number of medications suspected to be involved in the fall episode was often higher than the number identified as PIMs. Hence, a medication review may reduce the risk of medicationrelated falls but cannot eliminate it in all at-risk patients, suggesting that the prevalence of potentially avoidable medication-related fall-induced hip fractures might be markedly lower than $41 \%$. This suggests that trials exploring the effect of medication reviews either requires a very large number of participants with falls or should be targeted at high risk groups. Our data may guide studies on the latter. In line with this, it has yet to be proven that withdrawal of medications reduces the risk of falls $[9,14,20]$. The randomized study by Boye et al. [9] showed that withdrawal of FRIDs did not alter the fall rate or number of FRIDs after 12 months, and they proposed a lack of compliance with the withdrawal or prescription of new medications as possible explanations [9]. Accordingly, the number of FRIDs may actually increase after a hip fracture, [21] indicating that medication reviews among elderly patients should be a primary prophylactic modality. To select patients in whom to perform a medication review, our data points towards patients prescribed a higher number of medications and FRIDs, as these were the only obvious risk factors that detected those individuals with a suspected medicationrelated fall. The finding of a higher prevalence of ischaemic heart disease and previous fractures may be explained by an association of these conditions with a higher usage of medications.

We found that the most common FRIDs associated with suspected medication-related falls were psychotropic medications, particularly selective serotonin reuptake inhibitors and benzodiazepines or benzodiazepine-like medications, followed by antihypertensives and diuretics. This can be 
Table 2 The prevalence of comorbidities at the time of admission occurring in 5\% or more of patients

\begin{tabular}{|c|c|c|c|c|}
\hline & $\begin{array}{l}\text { Whole } \\
\text { population }\end{array}$ & $\begin{array}{l}\text { Patients without a } \\
\text { medication-related fall }\end{array}$ & $\begin{array}{l}\text { Patients with a } \\
\text { medication-related fall }\end{array}$ & $\begin{array}{l}P \text { value (patients with vs. } \\
\text { without a medication-related fall) }\end{array}$ \\
\hline$n(\%)$ & $200(100)$ & $118(59)$ & $82(41)$ & \\
\hline \multicolumn{5}{|l|}{ Prevalence of comorbidity ( $n(\%))$} \\
\hline Hypertension & $90(45)$ & $49(42)$ & $41(50)$ & 0.2 \\
\hline Osteoporosis & $46(23)$ & $28(24)$ & $18(22)$ & 0.8 \\
\hline Atrial fibrillation & $44(22)$ & $21(18)$ & $23(28)$ & 0.09 \\
\hline Previous ischaemic stroke & $36(18)$ & $21(18)$ & $14(17)$ & 0.9 \\
\hline Chronic obstructive pulmonary disease & $32(16)$ & $16(13)$ & $16(19)$ & 0.2 \\
\hline Dementia & $30(15)$ & $15(13)$ & $15(18)$ & 0.3 \\
\hline Previous fracture (hip or spine) & $29(14.5)$ & $12(10)$ & $17(20)$ & 0.04 \\
\hline Ischaemic heart disease & $27(13.5)$ & $11(9)$ & $20(24)$ & 0.04 \\
\hline Type 2 diabetes & $27(13.5)$ & $19(14)$ & $8(10)$ & 0.4 \\
\hline Chronic renal failure & $25(12.5)$ & $16(13)$ & $9(11)$ & 0.6 \\
\hline Depression & $22(11)$ & $9(7)$ & $13(16)$ & 0.07 \\
\hline Cancer & $18(9)$ & $12(10)$ & $6(7)$ & 0.5 \\
\hline Chronic heart failure & $14(7)$ & $10(8)$ & $4(5)$ & 0.3 \\
\hline Visual or hearing impairment & $14(7)$ & $13(7)$ & $10(7)$ & 0.9 \\
\hline Hyperthyreosis & $12(6)$ & $7(6)$ & $5(6)$ & 1 \\
\hline Arthrosis & $12(6)$ & $6(5)$ & $5(6)$ & 0.7 \\
\hline Hypothyreosis & $10(5)$ & $6(5)$ & $4(5)$ & 1 \\
\hline Chronic alcoholism & $10(5)$ & $5(4)$ & $4(5)$ & 1 \\
\hline
\end{tabular}

Table 2. Comorbidities at the time of admission with a prevalence of $5 \%$ or higher. One patient could have several diagnoses. Differences between patients with and without a medication-related fall were tested by the two-sample z-test

explained by the known adverse effects of these drugs $[6,8]$ and their widespread use. Thus, it is important to focus on these medications when performing medication reviews in order to reduce the risk of medication related falls. Nevertheless, thiazides may also have a beneficial effect on bone strength by increasing renal calcium reabsorption [22]. The use of medications with an established bone-demineralizing effect, such as oral corticosteroids, aromatase inhibitors and enzymeinducing anti-epileptics, was infrequent in our population, suggesting a limited contribution to falls by these medications among hip fracture patients. However, we could not evaluate the lifetime use of medications, and the long-term effect of prior use of such medications cannot be excluded in our study.

This study has several limitations. For one thing, the population is relatively small. The retrospective design implies that we had to rely on data obtained routinely and the possibility of focused examinations and interviews was precluded. The evaluation of clinical data and falls was not blinded to the list of medications, and the evaluations of the role of medications may have varied depending on the observer. On the other hand, the retrospective design [23] allowed us to study an unselected population of consecutive elderly patients with hip fractures, with access to clinical data, laboratory data and a detailed description of the fall episode. The validity of the description of the fall episode in the patient record is strengthened by the fact that this is a designated clinical task for the on-site consultant in geriatrics. Furthermore, the joint expertise of the clinical pharmacologist and the geriatrician in the evaluation of the individual patient records strengthens the evaluations and conclusions in our report. The female preponderance, age, high frequency of comorbidities, widespread use of medications, FRIDs, and PIMs in our patients correspond well to those from other studies of Danish and international cohorts of patients with hip fractures $[11,12,24-26]$. Thus, our population may be a representative sample of elderly patients with hip fracture. Altogether, we consider our result to be a qualified estimate of the prevalence of medication-related falls in elderly hip fracture patients.

\section{Conclusions}

The prevalence of suspected medication-related falls was $41 \%$ in elderly patients admitted with a hip fracture. It 
Table 3 Comparison of demographics, clinical parameters and use of medications for the groups 1 to 5 shown in Fig. 1

\begin{tabular}{|c|c|c|c|c|c|c|}
\hline \multirow{4}{*}{$\begin{array}{l}n(\%) \\
\text { Description }\end{array}$} & \multicolumn{6}{|l|}{ Group no. } \\
\hline & \multirow{3}{*}{$\begin{array}{l}1 \\
3(1.5)\end{array}$} & \multirow{3}{*}{$\begin{array}{l}2 \\
8(4) \\
\text { No } \\
\text { medication }\end{array}$} & \multirow{3}{*}{$\begin{array}{l}3 \\
59(29.5) \\
\text { Extrinsic factor } \\
\text { or tripping }\end{array}$} & \multirow{3}{*}{$\begin{array}{l}4 \\
48(24) \\
\text { Disease or } \\
\text { disability }\end{array}$} & 5 & \multirow{3}{*}{$\begin{array}{l}p \text {-value } \\
\text { (regression } \\
\text { with bootstrap) }\end{array}$} \\
\hline & & & & & $82(41)$ & \\
\hline & & & & & $\begin{array}{l}\text { Medication-related } \\
\text { fall }\end{array}$ & \\
\hline Age (years) & 78 [77-84] & $72[70-77.5]$ & $79[73-85]^{* \#}$ & $83[78.5-89]$ & 84 [77-89] & 0.0001 \\
\hline Body mass index $\left(\mathrm{kg} / \mathrm{m}^{2}\right)$ & $25 \pm 5$ & $25 \pm 4$ & $25 \pm 4$ & $24 \pm 4$ & $24 \pm 4$ & 0.7 \\
\hline SBP at admission (mmHg) & $182 \pm 27$ & $150 \pm 17$ & $150 \pm 25$ & $160 \pm 22$ & $150 \pm 27$ & 0.06 \\
\hline $\begin{array}{l}\text { Lowest SBP measured during } \\
\text { admission }(\mathrm{mmHg})\end{array}$ & $107 \pm 33$ & $116 \pm 17$ & $111 \pm 23$ & $111 \pm 20$ & $109 \pm 20$ & 0.8 \\
\hline PS at admission (\%) & $94 \pm 4$ & $97 \pm 3$ & $94 \pm 5$ & $94 \pm 4$ & $94 \pm 4$ & 0.1 \\
\hline TP at admission & $37.4 \pm 0.7$ & $36.6 \pm 0.7$ & $36.8 \pm 0.5 \#$ & $37.1 \pm 0.8$ & $36.9 \pm 0.6$ & 0.04 \\
\hline $\begin{array}{l}\text { Estimated glomerular filtration } \\
\text { rate }(\mathrm{ml} / \mathrm{min})\end{array}$ & $51[6-61]$ & $81.5[73-88]^{*}$ & $71[50-86]$ & $75[47-86]$ & $66[44-82]$ & 0.04 \\
\hline Sodium (mmol/l) & 140 [137-143] & 139 [136-141] & $140[138-141]^{*} \#$ & $137[135-141]$ & 138 [136-141] & 0.002 \\
\hline Number of drugs at admission & $11.6 \pm 5.1$ & - & $6.4 \pm 4.3^{*}$ & $6.4 \pm 3.3^{*}$ & $9.7 \pm 4.0$ & $<0.0001$ \\
\hline Number of FRIDS at admission & $2.3 \pm 1.2$ & - & $2.3 \pm 1.4^{*}$ & $1.75 \pm 1.3^{*}$ & $3.7 \pm 1.2$ & $<0.0001$ \\
\hline $\begin{array}{l}\text { Proportion of patients with } \\
\text { PIMs }(\mathrm{n}(\%))\end{array}$ & $3(100)$ & - & $34(57)+$ & $25(52)+$ & $79(96)$ & - \\
\hline
\end{tabular}

The table shows means \pm standard deviations for parametric data and medians [interquartile range] for nonparametric data. Differences in the numeric data between groups were analysed by regression with a bootstrap analysis; *: $p$-value $<0.05$ vs group 5 . \#: $p$-value $<0.05$ vs group 4 . Differences in the proportion of patients with PIMs were analysed by pairwise two-sample z-tests among groups 3, 4, and 5 ; t: $p$-value $<0.001$ vs group 5 . Abbreviations: SBP systolic blood pressure, PS peripheral saturation, TP temperature, FRIDS Fall-risk-increasing medications, PIMs Potentially inappropriate medications. Number of persons with missing data for each variable: age: 0, body mass index: $24(0,1,6,6$, and 11 in group 1, 2, 3, 4, and 5, respectively), SBP at admission: 2 (2 in group 5), lowest blood pressure during admission: 8 (1, 2, and 5 in group 3, 4, and 5, respectively), PS: 4 (4 in group 5), TP: 8 ( 2 and 6 in group 3 and 5, respectively), estimated glomerular filtration rate: 1 (1 in group 4), sodium; 2 (1 in group 4 and 5), number of drugs, FRIDs and PIMs: 0

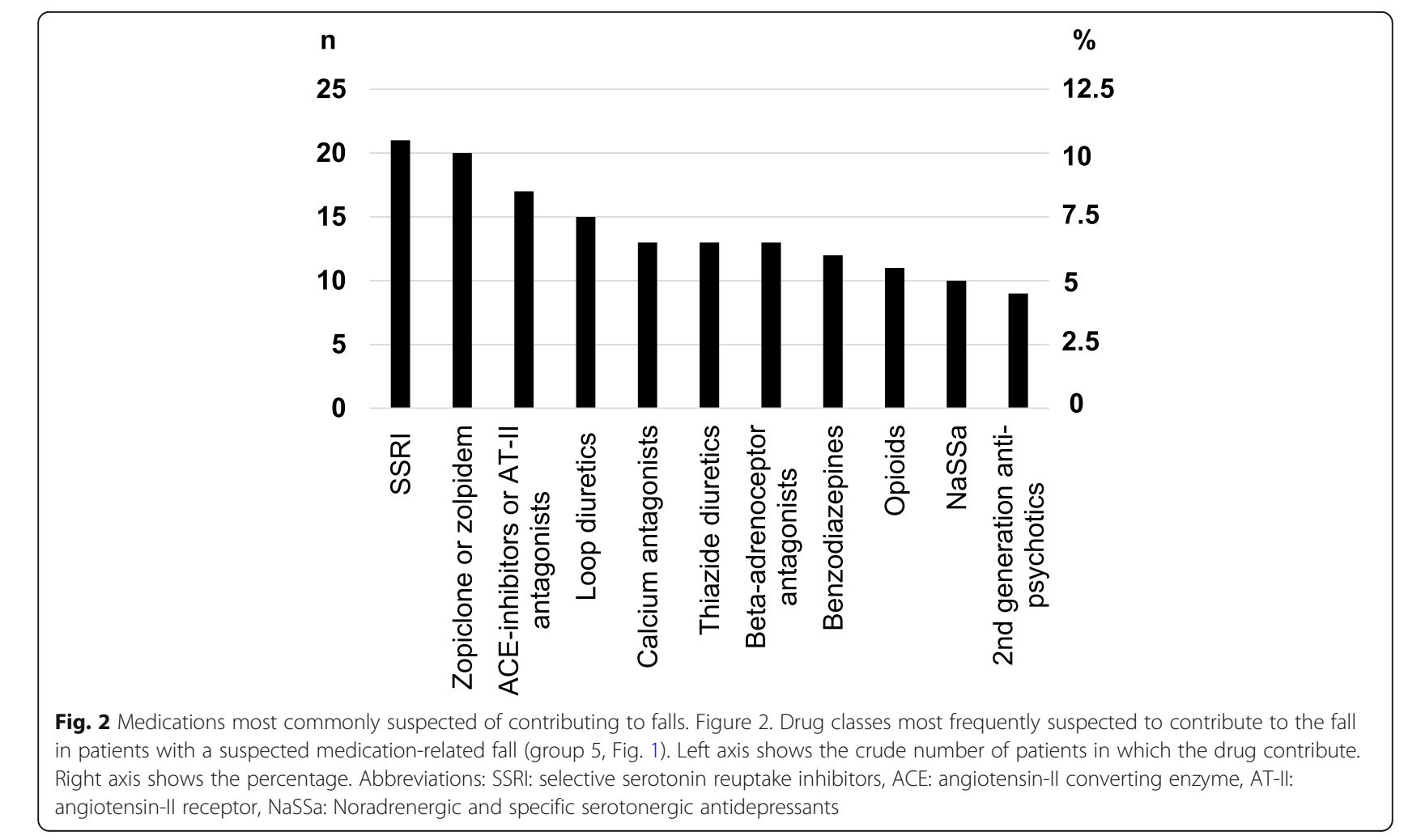


seems likely that a medication review followed by withdrawal of inappropriate medications could have reduced, though not eliminated, the risk of falling in 74 (37\%) of the total population. Still, intervention studies are warranted and the present data may support planning of such studies.

\section{Supplementary information}

Supplementary information accompanies this paper at https://doi.org/10. 1186/s12877-020-01532-9.

Additional file 1: Table S1. Medications used at the time of admission

\section{Abbreviations}

FRIDS: Fall-risk-increasing drugs; STOPP: Screening Tool of Older Persons' Prescriptions; PIMs: Potentially inappropriate medications; SD: Standard deviation; ACE: Angiotensin converting enzyme

\section{Acknowledgements}

Not applicable

\section{Authors' contributions}

CUA: Conception of idea, developing design, extraction and evaluation of patient data, literature search, analysis of results, manuscript writing. POL, HQU \& NA: Developing design, evaluation of patient data, literature search, and manuscript review. LPN \& SA: Developing design, literature search, and manuscript review. All authors read and approved the final manuscript.

\section{Funding}

No funding was received.

\section{Availability of data and materials}

The datasets generated and analysed during the current study are not publicly available because the Danish Patient Safety Authority has to approve transmission of the data to other researchers in each case. Data are, however, available from the authors upon reasonable request and with permission of the Danish Patient Safety Authority.

\section{Ethics approval and consent to participate}

The study was registered at the Danish Data Protection Agency. In accordance with Danish legislation (Act on Research Ethics Review of Health Research Projects $\S 14$ stk. 2 dated 15/09/2017 and the Danish Health Act § 46 stk. 2 dated 02/11/2018), the Danish Patient Safety Authority approved the project, including transmission of the data from the patient records. Data were handled in accordance with the Danish law on Personal Data Protection.

\section{Consent for publication}

The Danish Patient Safety Authority approved the project, including publication of the results.

\section{Competing interests}

The authors declare that they have no competing interests.

\section{Author details}

'Department of Clinical Pharmacology, Aalborg University Hospital, Mølleparkvej 8, 9000 Aalborg, Denmark. ${ }^{2}$ Department of Clinical Medicine, Aalborg University, Aalborg, Denmark. ${ }^{3}$ Department of Clinical Pharmacology, Aarhus University Hospital, Aarhus, Denmark. ${ }^{4}$ Department of Geriatric and Internal Medicine, Aalborg University Hospital, Aalborg, Denmark.

Received: 8 November 2019 Accepted: 23 March 2020

Published online: 30 March 2020

\section{References}

1. Hansen L, Mathiesen AS, Vestergaard P, Ehlers LH, Petersen KD. A health economic analysis of osteoporotic fractures: who carries the burden? Arch Osteoporos. 2013;8:126.
2. Menendez-Colino R, Alarcon T, Gotor P, Queipo R, Ramirez-Martin R, Otero $A$, et al. Baseline and pre-operative 1-year mortality risk factors in a cohort of 509 hip fracture patients consecutively admitted to a co-managed orthogeriatric unit (FONDA cohort). Injury. 2018:49:656-61.

3. Haentjens P, Magaziner J, Colon-Emeric CS, Vanderschueren D, Milisen K, Velkeniers $\mathrm{B}$, et al. Meta-analysis: excess mortality after hip fracture among older women and men. Ann Intern Med. 2010;152:380-90.

4. Zia A, Kamaruzzaman SB, Tan MP. The consumption of two or more fall riskincreasing drugs rather than polypharmacy is associated with falls. Geriatr Gerontol Int. 2017;17:463-70.

5. Bloch F, Thibaud M, Dugue B, Breque C, Rigaud AS, Kemoun G. Psychotropic drugs and falls in the elderly people: updated literature review and meta-analysis. J Aging Health. 2011;23:329-46.

6. De Vries M, Seppala LJ, Daams JG, van de Glind EMM, Masud T, van der Velde N, et al. Fall-Risk-Increasing Drugs: A Systematic Review and MetaAnalysis: I. Cardiovascular Drugs. J Am Med Dir Assoc. 2018;19:371 e1-9.

7. Seppala L, van de Glind EMM, Daams JG, Ploegmakers KJ, de Vries M, Wermelink A, et al. Fall-Risk-Increasing Drugs: A Systematic Review and Meta-analysis: III. Others. J Am Med Dir Assoc. 2018;19:372 e1-8.

8. Seppala LJ, Wermelink A, de Vries M, Ploegmakers KJ, van de Glind EMM, Daams JG, et al. Fall-Risk-Increasing Drugs: A Systematic Review and MetaAnalysis: II. Psychotropics. J Am Med Dir Assoc. 2018;19:371 e11-7.

9. Boye ND, van der Velde N, de Vries OJ, van Lieshout EM, Hartholt KA, Mattace-Raso FU, et al. Effectiveness of medication withdrawal in older fallers: results from the improving medication prescribing to reduce risk of FALLs (IMPROveFALL) trial. Age Ageing. 2017;46:142-6.

10. Beunza-Sola M, Hidalgo-Ovejero AM, Marti-Ayerdi J, Sanchez-Hernandez JG, Menendez-Garcia M, Garcia-Mata S. Study of fall risk-increasing drugs in elderly patients before and after a bone fracture. Postgrad Med J. 2018;94: 76-80.

11. Sjoberg C, Bladh L, Klintberg L, Mellstrom D, Ohlsson C, Wallerstedt SM. Treatment with fall-risk-increasing and fracture-preventing drugs before and after a hip fracture: an observational study. Drugs Aging. 2010;27:653-61.

12. Lonnbro J, Wallerstedt SM. Clinical relevance of the STOPP/START criteria in hip fracture patients. Eur J Clin Pharmacol. 2017;73:499-505.

13. O'Mahony D, O'Sullivan D, Byrne S, O'Connor MN, Ryan C, Gallagher P. STOPP/START criteria for potentially inappropriate prescribing in older people: version 2. Age Ageing. 2015:44:213-8.

14. Sjoberg C, Wallerstedt SM. Effects of medication reviews performed by a physician on treatment with fracture-preventing and fall-risk-increasing drugs in older adults with hip fracture-a randomized controlled study. J Am Geriatr Soc. 2013;61:1464-72

15. Ambrose AF, Paul G, Hausdorff JM. Risk factors for falls among older adults: a review of the literature. Maturitas. 2013;75:51-61.

16. Leavy B, Byberg L, Michaelsson K, Melhus H, Aberg AC. The fall descriptions and health characteristics of older adults with hip fracture: a mixed methods study. BMC Geriatr. 2015;15:40.

17. Hartholt KA, Boye ND, Van der Velde N, Van Lieshout EM, Polinder $\mathrm{S}$, De Vries OJ, et al. [Cost] effectiveness of withdrawal of fall-risk increasing drugs versus conservative treatment in older fallers: design of a multicenter randomized controlled trial (IMPROveFALL-study). BMC Geriatr. 2011;11:48.

18. Machado-Duque ME, Castano-Montoya JP, Medina-Morales DA, CastroRodriguez A, Gonzalez-Montoya A, Machado-Alba JE. Drugs with anticholinergic potential and risk of falls with hip fracture in the elderly patients: a case-control study. J Geriatr Psychiatry Neurol. 2018;31:63-9.

19. Harris PA, Taylor R, Thielke R, Payne J, Gonzalez N, Conde JG. Research electronic data capture (REDCap)--a metadata-driven methodology and workflow process for providing translational research informatics support. J Biomed Inform. 2009;42:377-81.

20. Guirguis-Blake JM, Michael YL, Perdue LA, Coppola EL, Beil TL. Interventions to prevent falls in older adults: updated evidence report and systematic review for the US preventive services task force. JAMA. 2018;319:1705-16.

21. Kragh A, Elmstahl S, Atroshi I. Older adults' medication use 6 months before and after hip fracture: a population-based cohort study. J Am Geriatr Soc. 2011:59:863-8.

22. Xiao $X, X \cup Y, W u Q$. Thiazide diuretic usage and risk of fracture: a metaanalysis of cohort studies. Osteoporos Int. 2018;29:1515-24.

23. Clemens KK, Ouedraogo A, Speechley M, Richard L, Thain J, Shariff SZ. Hip fractures in older adults in Ontario, Canada-monthly variation, insights, and implications. Can Geriatr J. 2019;22:148-64. 
24. Boddaert J, Cohen-Bittan J, Khiami F, Le Manach Y, Raux M, Beinis JY, et al. Postoperative admission to a dedicated geriatric unit decreases mortality in elderly patients with hip fracture. PLoS One. 2014;9:e83795.

25. Jantzen C, Madsen CM, Abrahamsen B, Van Der Mark S, Duus BR, Howland J, et al. Pre-fracture medication use as a predictor of 30-day mortality in hip fracture patients: an analysis of 141,201 patients. Hip Int. 2019;101-106. https://doi.org/10.1177/1120700019832603.

26. Frederiksen A, Abrahamsen B, Johansen PB, Sorensen HA. Danish, national cross-sectional observational study on the prevalence of prior major osteoporotic fractures in adults presenting with hip fracture-limitations and scope for fracture liaison services in prevention of hip fracture. Osteoporos Int. 2018;29:109-14.

\section{Publisher's Note}

Springer Nature remains neutral with regard to jurisdictional claims in published maps and institutional affiliations.

Ready to submit your research? Choose BMC and benefit from:

- fast, convenient online submission

- thorough peer review by experienced researchers in your field

- rapid publication on acceptance

- support for research data, including large and complex data types

- gold Open Access which fosters wider collaboration and increased citations

- maximum visibility for your research: over $100 \mathrm{M}$ website views per year

At BMC, research is always in progress.

Learn more biomedcentral.com/submissions 